GAIA, J.M.D.; MOTA, M.G.C.; DERBYSHIRE, M.T.V.C.; OLIVEIRA, V.R.; COSTA, M.R.; MARTINS, C.S.; POLTRONIERI, M.C. Diversidade e similaridade genéticas em clones de pimenta-do-reino. Horticultura Brasileira, Brasília, v.23, n.2, p.221-227, abr-jun 2005.

\title{
Diversidade e similaridade genéticas em clones de pimenta-do-reino
}

\author{
José M.D. Gaia'; Milton G.C. Mota ${ }^{1}$; Maria Tereza V.C. Derbyshire ${ }^{2}$; Viseldo R. Oliveira ${ }^{2}$; Maria R. \\ Costa $^{3}$; Carlos da S. Martins ${ }^{3}$; Marli C. Poltronieri ${ }^{3}$ \\ ${ }^{1}$ Universidade Federal Rural da Amazônia, ICA, C. Postal 917, 66077-530 Belém-PA; ${ }^{2}$ Centro de Energia Nuclear na Agricultura, C. \\ Postal 96, 13400-970 Piracicaba-SP; ${ }^{3}$ Embrapa Amazônia Oriental, C. Postal 48, 66095-100 Belém-PA³; E- \\ mail:josegaia@interconect.com.br
}

\section{RESUMO}

Setenta e oito clones de pimenta-do-reino (Piper nigrum L.) foram analisados por meio de eletroforese de isozimas para os sistemas ACP, GOT, SKDH, ACO, G6PDH, PGI, 6PGDH e FUM, para avaliar a diversidade por meio da porcentagem de locos polimórficos, número médio de alelos por locos e heterozigosidade média. A similaridade genética foi obtida por meio do coeficiente de semelhança simples e foi resumida num fenograma de média de grupo. Foram detectados 14 locos e 35 alelos. Os locos que apresentaram maior diversidade foram: G6pdh-1, Acp-1 e Skdh-1. A porcentagem de locos polimórficos variou de $3,57 \%$ a $64,29 \%$; o número médio de alelos variou de 0,04 a 1,64; e a heterozigosidade média variou de 0,036 a 0,321 . Os baixos valores observados no intervalo de variação da heterozigosidade média são consistentes com a estreita base genética dos genótipos e a amplitude deste intervalo pode estar relacionada com o grau de hibridação (artificial ou natural) de cada clone. A similaridade genética variou de $65 \%$ a $100 \%$, sendo que 70 clones estiveram contidos na faixa de $85 \%$ e $100 \%$, o que ratifica o estreitamento da base genética da espécie e conseqüente homogeneidade dos genomas cultivados.

Palavras chave: Piper nigrum L., germoplasma, isozimas, melhoramento genético.

\begin{abstract}
Genetic diversity and similarity in clones of black pepper

Seventy eight black pepper clones (Piper nigrum L.) were analyzed by means of isozyme electrophoresis for the systems ACP, GOT, SKDH, ACO, G6PDH, PGI, 6PGDH and FUM, in order to evaluate the diversity through the percentage of polymorphic loci, mean number of alleles per locus and mean heterozigosity. Genetic similarity was calculated by simple matching coefficient and summarized in the group average phenogram. Fourteen loci and 35 alleles were detected. The loci that presented larger diversity were G6pdh-1, Acp-1 and Skdh-1. The percentage of polymorphic loci ranged from $3.57 \%$ to $64.29 \%$; the mean number of alleles ranged from 0.04 to 1.64 and; the mean heterozigosity varied from 0.036 to 0.321 . The lower values observed in the interval of variation of the average heterozigosity are consistent with the narrow genetic basis and the width of this interval can be related to the natural or forced hybridization degree of each clone. The genetic similarity ranged from $65 \%$ to $100 \%$, and 70 clones were ranked into the interval of $85 \%$ to $100 \%$, which confirms the narrowing of the genetic basis of the species and thereby resulting in the homogeneity of the cultivated clones.
\end{abstract}

Keywords: Piper nigrum L., genetic breeding, germplasm, isozymes.

\section{(Recebido para publicação em 10 de janeiro de 2004 e aceito em 10 de fevereiro de 2005)}

\begin{abstract}
$A_{1}$ pimenta-do-reino (Piper nigrum L.) é um arbusto trepador, perene, da família das piperáceas (ZEVEN, 1974), sendo importante produto agrícola para o Brasil, particularmente ao estado do Pará (IBGE, 2002).

A coleção de germoplasma de pimenta-do-reino (Embrapa Amazônia Oriental) é constituída por clones, a maioria procedente da Estação Experimental Federal de Mayaguez (Porto Rico) e muito provavelmente provenientes da última introdução da espécie nas Américas, ocorrida na ilha de Guadalupe, em 1942 (RODRIGUES, 1967). A grande maioria dos clones é originária da Índia ou derivada de clones indianos (ALBUQUERQUE, 1998) ${ }^{1}$.
\end{abstract}

A estreita base genética, a homogeneidade dos clones cultivados e a suscetibilidade a doenças são devidas ao cultivo de somente um ou alguns clones (ZEVEN, 1974) que, aliadas aos limitados conhecimentos sobre a genética da espécie, constituem-se nos principais problemas para a obtenção de genótipos superiores, não obstante o fato de tradicionais e modernas técnicas de melhoramento já terem sido utilizadas.

Martins et al. (1996) detectaram diferenças genéticas (polimorfismo) entre os acessos de pimenta-do-reino do banco de germoplasma da Embrapa Amazônia Oriental por meio de análise de isozimas nos sistemas MDH, SKDH, 6PGDH, IDH, PGI e ME. Cortez e
Hunziker (1997) analisaram a variação isozimática em populações diplóides e tetraplóides de duas espécies nativas do deserto da California e da América do Sul conhecidas vulgarmente como "creosote bush" (Larrea divaricata e $L$. Tridentata) e observaram que a faixa de similaridade no dendrograma, pelo método de Nei (1972), variou de $87 \%$ a $100 \%$, apresentando, portanto, uma faixa de variação semelhante à observada nos acessos de pimenta-do-reino que é, segundo Mathew (1973), uma espécie tetraplóide diploidizada.

Um dos muitos usos das isozimas como marcadores genéticos está em sua capacidade em detectar genes sinalizadores de resistência a doenças.

\footnotetext{
${ }^{1}$ ALBUQUERQUE, F. C. de. Comunicação pessoal . Belém-PA: Embrapa Amazônia Oriental, 1998.
} 
Em tomate, a isozima Aps-1, do sistema fosfatase ácida, foi localizada a um centimorgan $(1 \mathrm{cM})$ de um loco que controla a resistência ao nematóide Meloidogyne incognita (MEDINA-FILHO, 1980).

A heterozigosidade ou diversidade genética é a medida mais importante e a mais utilizada para estimar a variabilidade genética e é menos sensível às variações no tamanho da amostra quando comparada a outras medidas, tais como a porcentagem de locos polimórficos e o número médio de alelos por locos e possui fácil interpretação em termos genéticos (BROWN; WEIR, 1983). Nos casos em que a proporção de heterozigotos não pode ser definida conforme as suposições de equilíbrio, a heterozigosidade deve ser compreendida apenas como uma medida de variabilidade, devendo ser mais convenientemente chamada de diversidade genética (TORGGLER et al., 1995).

Este trabalho teve por objetivo caracterizar a diversidade genética da coleção de germoplasma de pimenta-doreino da Embrapa/Amazônia Oriental, assim como identificar os clones mais divergentes para que possam ser utilizados na obtenção de genótipos superiores aos atuais existentes.

\section{MATERIAL E MÉTODOS}

Foram utilizados 78 acessos da coleção de germoplasma da Embrapa Amazônia Oriental em Belém (Tabela 1). Amostras unitárias foram adotadas levando em conta que as plantas cultivadas de pimenta-do-reino são autógamas (WAARD; ZEVEN, 1969); que os clones cultivados apresentam homogeneidade genética, donde pode-se inferir uma estreita base genética da espécie (ZEVEN, 1974); além de serem propagadas vegetativamente, por estacas.

A metodologia e os procedimentos utilizados para coleta de tecido vegetal, extração de proteínas, formulação dos tampões e do sistema de géis (separador e concentrador), implementação da eletroforese, avaliação do tempo de corrida, análise das condições de migração e revelação das enzimas foram baseados em Tsumura et al. (1990), com as seguintes adaptações para pimenta-do- reino: 1) utilizaram-se $50 \mathrm{mg}$ de tecido foliar jovem para a maceração sob nitrogênio líquido e, simultaneamente, cerca de $75 \mathrm{mg}$ de PVPP adicionado a 1 ml do tampão de extração; 2) a eletroforese foi realizada sob condições de $16 \mathrm{~mA}$ durante cerca de cinco horas; 3) as soluções corantes de fosfoglucoisomerase (PGI) e fosfatase ácida (ACP) foram modificadas para $50 \mathrm{ml}$ de Tris- $\mathrm{HCl}, 50 \mathrm{mM}$, $\mathrm{pH} 8,0 ; 1 \mathrm{ml}$ de D-frutose-6-fosfato $(20 \mathrm{mg} / \mathrm{ml}) ; 1 \mathrm{ml}$ de NADP $(6,6 \mathrm{mg} / \mathrm{ml}) ; 2 \mathrm{ml}$ de MTT $(5 \mathrm{mg} / \mathrm{ml}) ; 1 \mathrm{ml} \mathrm{de} \mathrm{PMS}(5 \mathrm{mg} / \mathrm{ml}), 1 \mathrm{ml}$ de cloreto de magnésio $(10,17 \mathrm{~g} / 100 \mathrm{ml})$ e 10 unidades de G6PDH (PGI); 50ml de "ACP buffer" (1,6 g de acetato de sódio tri-hidratado, 4,83ml de ácido glacial acético e $500 \mathrm{ml}$ de água destilada); $100 \mathrm{mg}$ de $\alpha$-naftil fosfato, sal dissódico e 12 mg de "Fast garnet GBC salt" (ACP).

Além de fosfoglucoisomerase (PGI, 5.3.1.9) e fosfatase ácida (ACP, 3.1.3.2), foram utilizados mais seis sistemas enzimáticos: aconitase (ACO, 4.2.1.3), 6-fosfogluconato desidrogenase (6PGDH, 1.1.1.44), fumarase (FUM, 4.2.1.2), glucose-6-fosfato desidrogenase (G6PDH, 1.1.1.49), glutamato oxaloacetato transaminase (GOT, 2.6.1.1) e xiquimato desidrogenase (SKDH, 1.1.1.25).

Os padrões de bandas revelados nos géis (fenótipos) foram desenhados em zimogramas, segundo os valores da mobilidade relativa (Rf) de cada banda, definida como a razão entre a distância percorrida por cada banda (d) e a distância percorrida pela linha do azul-debromofenol (D), conforme Cheliak e Pitel (1984).

Os alelos foram codificados conforme proposto por Neale et al. (1984), em que o alelo que controla a isozima de migração mais rápida recebe a letra "a", em cada loco. O loco mais anódico, por sua vez, recebe o número um.

A diversidade genética foi avaliada por meio de três parâmetros: 1) a porcentagem de locos polimórficos $(\mathrm{P})$, definida pela razão entre o número de locos polimórficos e o número total de locos; 2) o número médio de alelos por locos (A), que é dado pela razão entre a somatória do número de alelos nos locos polimórficos e o número de locos ob- servados; e 3) heterozigosidade média, que é dada pela média das quantidades de $\mathrm{h}\left(\mathrm{h}=1-\Sigma \mathrm{p}_{\mathrm{i}}^{2}\right)$ para todos os locos examinados em uma determinada amostra (NEI, 1987). Foi determinada a similaridade genética baseada no coeficiente de semelhança simples e o fenograma gerado foi baseado na média de grupo pela utilização do programa Fitopac 1 (SHEPHERD, 2001).

\section{RESULTADOS E DISCUSSÃO}

Foram observados 35 alelos nos 14 locos analisados, sendo que 12 foram polimórficos e em somente dois (G6pdh-1 e Fum-1) ocorreram exclusivamente indivíduos homozigotos. Dentre os locos polimórficos, aqueles que apresentaram maior polimorfismo foram G6pdh-2, Acp-1 e Skdh-1. Dentre os 14 locos analisados dois apresentaram quatro alelos (Got-1 e Aco-1), cinco tiveram três alelos (Got-2, Skdh-1, Acp-1, 6Pgdh-2 e 6Pgdh-3); cinco apresentaram dois alelos (G6pdh-2, 6Pgdh1, Pgi-1, Pgi-2 e Pgi-3) e os locos Fum1 e G6pdh-1 apresentaram somente um alelo.

A Figura 1 contém um zimograma dos alelos e locos observados nos oito sistemas enzimáticos analisados. $\mathrm{O}$ sistema GOT apresentou uma zona (a mais catódica) com baixa definição das bandas, sendo, por este motivo, não considerada nesta análise. Tais bandas costumam estar relacionadas com herança mitocondrial e macho-esterilidade, que é um caráter de grande importância agronômica, sendo utilizado na produção de híbridos, dispensando a emasculação manual (PETERS; JAIN, 1987; ILARSLAN et al., 1999 e VIANA et al., 2001). Horacek e Acanová (2003) observaram locos catódicos de PGI (menor migração) com menor intensidade de bandas e atribuíram isto ao fato de haver um maior número de alelos no loco mais anódico, apresentando este loco ligação com genes restauradores da fertilidade em plantas de nabo (Brassica napus L var. napus).

O sistema SKDH apresentou o primeiro alelo um pouco mais separado dos outros dois, porém não parecendo constituir um outro loco, pois esteve presente em poucos indivíduos assumindo uma 
Tabela 1. Relação dos acessos de pimenta-do-reino da coleção de germoplasma do CPATU analisados, com seus respectivos nomes. Belém, ICA/UFRA, 1999/00.

\begin{tabular}{|c|c|c|c|c|c|}
\hline Código ${ }^{1}$ & Acesso & Código & Acesso & Código & Acesso \\
\hline $\mathrm{C} 01$ & 0697 & $\mathrm{C} 27$ & Piper Colubrinum Link & C53 & $\mathrm{X} 18$ \\
\hline $\mathrm{C} 02$ & Cingapura & $\mathrm{C} 28$ & Kottanadan-2 & C54 & $\mathrm{X} 32$ \\
\hline $\mathrm{CO3}$ & Diemberg (Acesso 1) & C29 & Karimunda-3 & C55 & 45 \\
\hline $\mathrm{CO4}$ & Djambi (Acesso 1) & $\mathrm{C} 30$ & Piper Attenuatum-F & C56 & 132 \\
\hline C05 & Balankotta (Acesso 1) & C31 & Diemberg (Ac. 3, ind-2) & C57 & $C z-5 \times 10$ \\
\hline $\mathrm{C} 06$ & Q.D.S. PL.-F6 & $\mathrm{C} 32$ & laçará-2 & C58 & P3 \\
\hline $\mathrm{C} 07$ & Perunkoide-S & C33 & Q.B. $5 \times 10-S$ & C59 & Mangueira \\
\hline $\mathrm{C} 08$ & Piper Attenuatum-M1 & C34 & Papari & $\mathrm{C} 60$ & Kovt (kottavally) \\
\hline C09 & Piper Attenuatum-M2 & C35 & Diemberg (Acesso 2) & C61 & 239 \\
\hline $\mathrm{C} 10$ & Piper Attenuatum-M3 & C36 & Cz-4X11 (Acesso 1) & $\mathrm{C} 62$ & U.T. (Uthirankotta) \\
\hline C11 & Guajarina (karimunda) & C37 & Chumala-S & C63 & 1558 \\
\hline $\mathrm{C} 12$ & Karimunda & C38 & Bragantina (Acesso 1) & C64 & Trang \\
\hline $\mathrm{C} 13$ & Chumala & C39 & laçará-1 & C65 & Diemberg (Acesso 3) \\
\hline C14 & Belantung & C40 & Kuching & $\mathrm{C} 66$ & Uthirankotta (progênie) \\
\hline C15 & Djambi (Acesso 2) & C41 & Piper Attenuatum-X & $\mathrm{C} 67$ & Uthirankotta (mãe) \\
\hline C16 & Balankotta (Acesso 2) & C42 & Kudaravalli & C68 & Guajarina (acesso 2) \\
\hline $\mathrm{C} 17$ & Espírito Santo & C43 & Pimenta-da-terra & C69 & Karimunda-S \\
\hline C18 & Bragantina 6.3.92 & C44 & Diemberg (Ac. 2, ind-2) & $\mathrm{C} 70$ & Uthirankotta-S (Apra) \\
\hline C19 & Cingapura 6.3 .92 & C45 & F1-PL8 & C71 & laçará-S \\
\hline $\mathrm{C} 20$ & laçará-1 (ind-2) & C46 & Bragantina (Acesso 2) & $\mathrm{C} 72$ & S-2 \\
\hline $\mathrm{C} 21$ & F6-PL1 & C47 & Cz-4x11 (Acesso 2) & $\mathrm{C} 73$ & Balankotta Jones \\
\hline $\mathrm{C} 22$ & S-1 & C48 & Kaluvalli (Acesso 2) & $\mathrm{C} 74$ & Guajarina-INATAM \\
\hline $\mathrm{C} 23$ & G-1 & C49 & $\mathrm{X} 1$ & $\mathrm{C} 75$ & Pan-1-CEN (Pannyiur-1) \\
\hline $\mathrm{C} 24$ & Piper betle & C50 & $\mathrm{X} 26$ & C76 & BAG $16 \times 13$ \\
\hline $\mathrm{C} 25$ & Karimunda-2 & C51 & X3 & C77 & Kaluvalli (Ac 2, ind-2) \\
\hline C26 & Kottanadan-1 & C52 & B & C78 & Kudaravalli (ind-2) \\
\hline
\end{tabular}

${ }^{1}$ : Notação adotada para as análises no programa de computador.

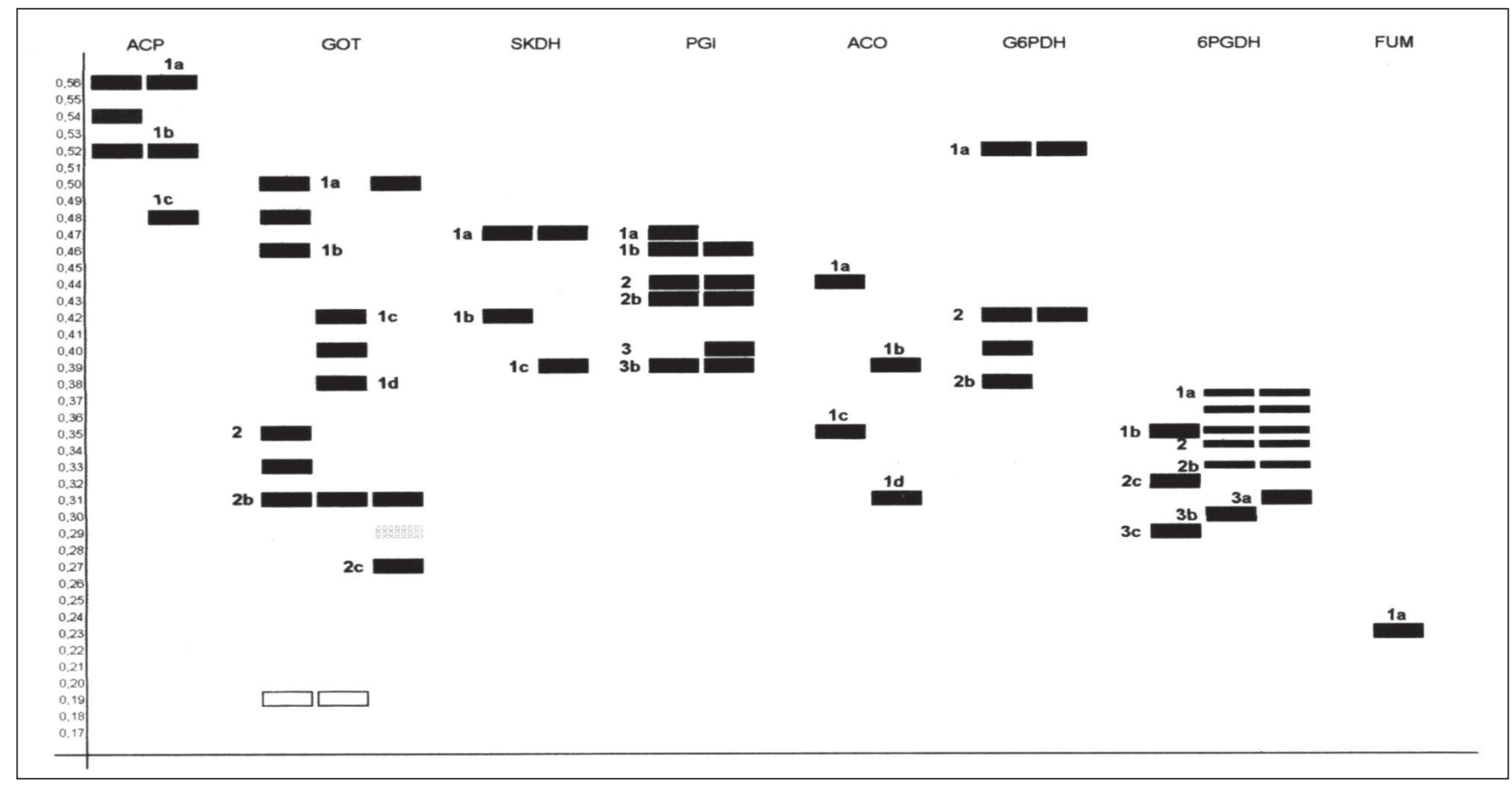

Figura 1. Zimograma dos alelos e locos observados nos oito sistemas enzimáticos analisados. Foram observados 35 alelos e 14 locos, sendo que 12 foram polimórficos e em somente dois (G6phd-1 e Fum-1) ocorreram exclusivamente indivíduos homozigotos. Belém-ICA/UFRA, 1999/00. 


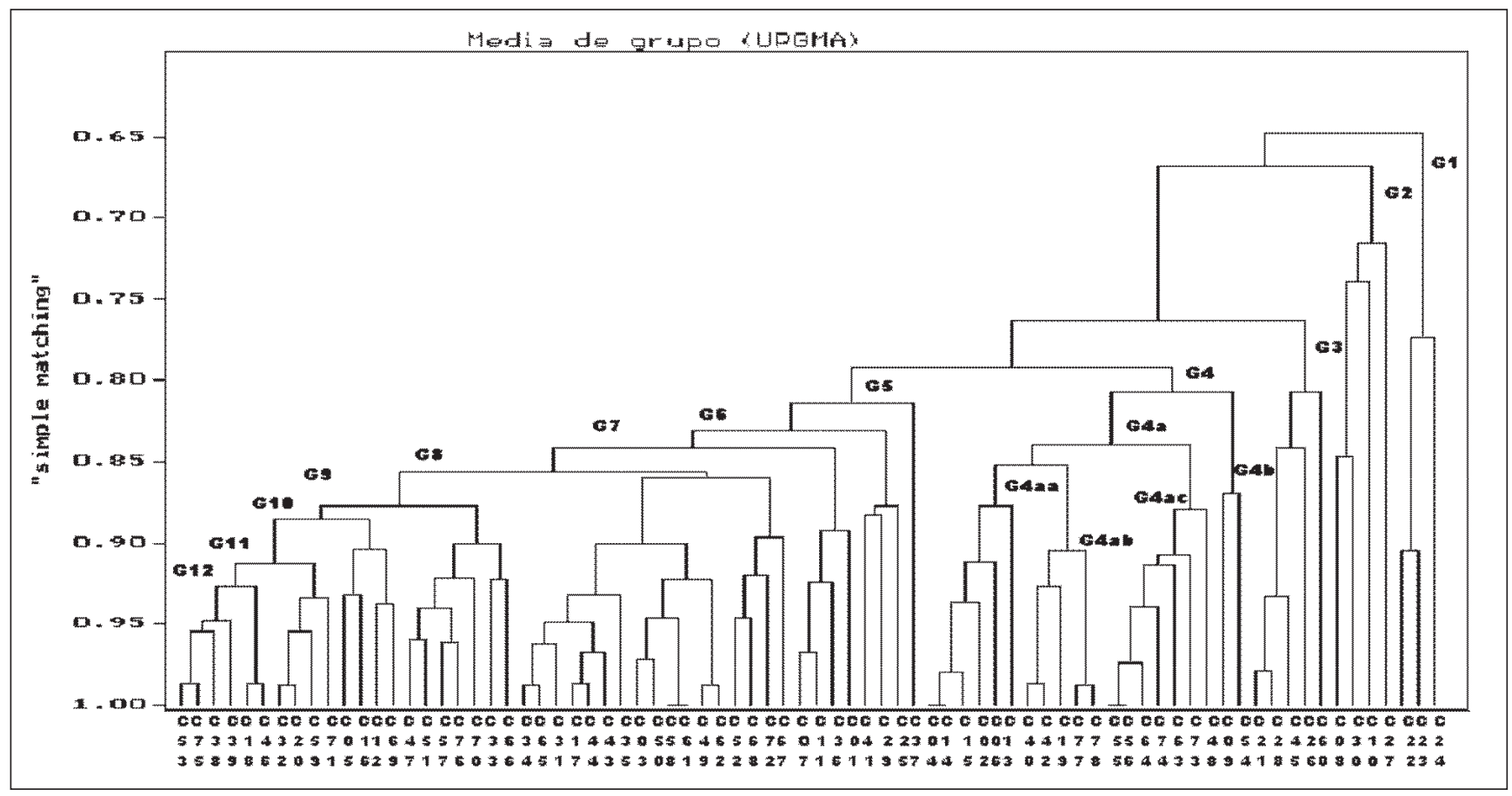

Figura 2. Fenograma de agrupamento de 78 acessos de pimenta-do-reino da coleção de germoplasma da Embrapa Amazônia Oriental, gerado pelo método UPGMA, com similaridades calculadas pelo coeficiente de semelhança simples ("simple matching"). O fenograma foi dividido em 12 grupos (G1, G2. G3. G4, G5, G6, G7, G8, G9, G10, G11, e G12). Belém-ICA/UFRA, 1999/00.

única forma. O sistema PGI, embora comumente apresente estrutura dimérica, em pimenta-do-reino observou-se possivelmente três locos com estrutura monomérica. Isto pode ser devido a várias características particulares da pimenta-do-reino, tais, a diploidização de poliplóides (autopoliplóides ou alopoliplóides), causando variação no número de cromossomos da espécie (WAARD; ZEVEN, 1969) ou mesmo pode ter havido a perda da banda heterodimérica no transcorrer do processo evolutivo, sendo que esta possibilidade também foi considerada, em arroz (Oriza sativa e O. minuta), por Romero et al. (1993), ao observar zonas eletroforéticas de PGI com duas bandas. $\mathrm{O}$ sistema 6PGDH apresentou, igualmente, nos dois locos mais catódicos, estrutura possivelmente monomérica.

Na Tabela 2 há os valores da heterozigosidade por loco e acesso, do número médio de alelos por loco, da porcentagem de locos polimórficos e da heterozigosidade média por acesso. $\mathrm{O}$ número médio de alelos (A) variou de 0,04 (clone CO3) a 1,64 (clones C40, C73, C74 e C78). Valor inferior ao des- ta faixa foi observado em café falso (Faramea occidentalis L.) (HAMRICK; LOVELESS, 1986) e valor superior foi observado em laranja do monte (Swartzia simplex var. grandiflora) (HAMRICK; LOVELESS, 1986).

A porcentagem de locos polimórficos (P) variou de 3,57\% a $64,29 \%$. Valores superiores a $50 \%$ foram observados em somente nove clones (C37, C40, C42, C45, C63, C73, C74, C77, C78). Por outro lado, doze acessos tiveram índices de polimorfismos, com valores abaixo de 10\% (C01, C03, C07, C11, C20, C22, C23, C31, C51, C54, C59 e C71). Em literatura observou-se que zero foi o menor valor para $\mathrm{P}$, em café falso, sem critério definido pelos autores (Hamrick e Loveless, 1986); e o maior valor observado foi de $64,30 \%$, sob o critério de 0,95 , em "japonese beech" (Fagus crenata Blume) (TAKAHASHI et al., 1994).

A heterozigosidade média (h) por acesso variou de 0,036 (clones C52, C54, C71 e C03) a 0,321 (C40, C73, C74 e C78). A variação observada em literatura foi de 0,142 em populações de tremoço (Lupinus subcarnosus) (Babbel e Selander, 1974) a 0,448 em cultivares híbridos de arroz (WAN; IKEHASHI, 1997).

A ampla faixa de variação da heterozigosidade média observada em pimenta-do-reino talvez esteja vinculada ao processo evolutivo das espécies que passam por hibridação seguida de fixação de heterozigose em clones. Todavia, esta faixa, quando comparada com a observada em cultivares híbridos de $\operatorname{arroz}(0,386$ a 0,448$)$ (WAN; IKEHASHI, 1997), possui valores menores, o que pode ser devido à base genética estreita da pimenta-do-reino, apesar da hibridação artificial ocorrida ao longo do processo de domesticação.

No fenograma da Figura 2 há os agrupamentos dos 78 acessos. Houve formação de 12 grupos, sendo que os grupos G1, G2 e G3 foram os mais divergentes em relação ao conjunto. $\mathrm{O}$ grupo G5 está constituído por um único clone (C37) que, de certo modo, está dividindo o fenograma em duas partes. A grande maioria dos clones a sua esquerda apresentaram similaridade tanto dentro quanto entre grupos/subgrupos abaixo do nível de $85 \%$. Isto é particularmente observado do grupo G8 em diante, constituindo um total de 38 
Tabela 2. Heterozigosidade por loco e acesso (h), número médio de alelos por locos (A), porcentagem de locos polimórficos (P) e heterozigosidade média por acesso (H) em pimenta-do-reino. Belém-ICA/UFRA, 1999/00.

\begin{tabular}{|c|c|c|c|c|c|c|c|c|c|c|c|c|c|c|c|c|c|}
\hline \multirow{3}{*}{ Acesso } & \multicolumn{14}{|c|}{ Locos } & \multirow{3}{*}{ A } & \multirow{3}{*}{$\mathbf{P}$} & \multirow{3}{*}{ H } \\
\hline & Got-1 & Got-2 & Skdh-1 & Acp-1 & Fum-1 & Aco-1 & $\begin{array}{c}\text { G6 } \\
\text { pdh-1 }\end{array}$ & $\begin{array}{c}\text { G6 } \\
\text { pdh-2 }\end{array}$ & $\begin{array}{c}6 \\
\text { pgdh-1 }\end{array}$ & $\begin{array}{c}6 \\
\text { pgdh-2 }\end{array}$ & $\begin{array}{c}6 \\
\text { pgdh-3 }\end{array}$ & Pgi-1 & Pgi-2 & Pgi-3 & & & \\
\hline & h & $\mathbf{h}$ & h & $\mathbf{h}$ & h & $\mathbf{h}$ & $\mathbf{h}$ & $\mathbf{h}$ & $\mathbf{h}$ & $\mathbf{h}$ & $\mathbf{h}$ & $\mathbf{h}$ & $\mathrm{h}$ & $\mathrm{h}$ & & & \\
\hline C01 & 0 & 0,5 & 0 & 0 & 0 & 0 & 0 & 0,5 & 0 & 0 & 0 & 0 & 0 & 00 & 0,07 & 7,14 & 0,071 \\
\hline $\mathrm{C} 02$ & 0 & 0 & 0 & 0,5 & 0 & 0 & 0 & 0,5 & 0 & 0,5 & 0,5 & 0 & 0 & 0 & 0,14 & 14,29 & 0,143 \\
\hline $\mathrm{C} 03$ & 0 & 0 & -- & 0 & 0 & 0 & 0 & 0,5 & 0 & 0 & 0 & 0 & 0 & 0 & 0,04 & 3,57 & 0,036 \\
\hline $\mathrm{CO4}$ & 0 & 0 & 0,5 & 0,5 & 0 & 0,5 & 0 & 0,5 & 0 & 0,5 & 0,5 & 0 & 0 & 0 & 0,21 & 21,43 & 0,214 \\
\hline C05 & 0,5 & 0 & 0,5 & 0 & 0 & 0,5 & 0 & 0,5 & 0 & 0 & 0 & 0 & 0 & 0 & 0,14 & 14,29 & 0,143 \\
\hline C06 & 0,5 & 0,5 & 0 & 0 & 0 & 0 & 0 & 0,5 & 0 & 0,5 & 0,5 & 0 & 0 & $x$ & 0,19 & 19,23 & 0,192 \\
\hline $\mathrm{C} 07$ & 0 & 0,5 & 0 & - & 0 & 0 & 0 & 0,5 & 0 & 0 & 0 & 0 & 0 & 0 & 0,08 & 7,69 & 0,077 \\
\hline C08 & 0 & 0,5 & 0,5 & - & 0,5 & 0 & 0 & 0 & $x$ & 0,5 & $x$ & 0 & 0 & -- & 0,20 & 20,00 & 0,200 \\
\hline C09 & 0 & 0,5 & 0,5 & -- & -- & -- & -- & --- & $x$ & 0,5 & 0,5 & 0 & 0 & 0,5 & 0,31 & 31,25 & 0,313 \\
\hline $\mathrm{C} 10$ & 0 & 0,5 & 0,5 & 0,5 & 0,5 & 0 & 0 & 0 & $x$ & 0,5 & 0,5 & 0 & 0 & 0,5 & 0,25 & 25,00 & 0,250 \\
\hline C11 & 0 & 0,5 & 0,5 & -- & 0 & 0 & -- & -- & 0 & 0 & 0 & 0 & 0 & 0 & 0,08 & 8,33 & 0,083 \\
\hline C12 & 0,5 & 0 & 0,5 & -- & 0 & 0,5 & 0 & 0,5 & 0 & 0 & 0 & 0 & 0 & 0 & 0,15 & 15,38 & 0,154 \\
\hline $\mathrm{C} 13$ & 0 & 0 & 0 & 0 & 0 & 0 & 0 & 0,5 & 0,5 & 0,5 & 0 & 0 & 0 & 0 & 0,11 & 10,71 & 0,107 \\
\hline C14 & 0 & 0 & 0,5 & 0 & 0 & 0,5 & 0 & 0,5 & 0 & 0,5 & 0,5 & 0 & 0 & 0 & 0,18 & 17,86 & 0,179 \\
\hline $\mathrm{C} 15$ & 0 & 0 & 0,5 & 0 & 0 & 0 & 0 & 0,5 & 0 & 0,5 & 0,5 & 0 & 0 & 0 & 0,14 & 14,29 & 0,143 \\
\hline C16 & 0,5 & 0 & 0,5 & 0,5 & 0 & 0,5 & 0 & 0,5 & 0 & 0 & 0 & 0 & 0 & 0 & 0,17 & 16,67 & 0,167 \\
\hline C17 & 0 & 0 & 0,5 & 0,5 & 0 & 0 & 0 & 0,5 & 0 & 0 & 0 & 0 & 0 & 0 & 0,13 & 13,33 & 0,133 \\
\hline C18 & 0 & 0,5 & 0,5 & 0,5 & 0 & 0,5 & 0 & 0,5 & 0 & 0 & 0 & 0 & 0 & 0 & 0,18 & 17,86 & 0,179 \\
\hline C19 & 0,5 & 0,5 & 0,5 & 0 & 0 & 0 & 0 & 0,5 & 0 & 0,5 & 0,5 & 0 & 0 & 0,5 & 0,25 & 25,00 & 0,250 \\
\hline C20 & 0 & 0,5 & 0,5 & 0 & 0 & 0 & 0 & 0 & 0 & 0 & 0 & 0 & 0 & 0 & 0,07 & 7,14 & 0,071 \\
\hline $\mathrm{C} 21$ & $x$ & $x$ & 0 & 0,5 & 0 & $x$ & 0 & 0,5 & 0,5 & 0,5 & 0 & 0 & 0 & $x$ & 0,20 & 20,00 & 0,200 \\
\hline C22 & $x$ & 0 & 0,5 & $x$ & $x$ & 0 & $x$ & $x$ & 0 & 0 & 0 & 0 & $x$ & 0 & 0,06 & 5,56 & 0,056 \\
\hline C23 & 0 & 0,5 & 0,5 & $x$ & 0 & $x$ & 0 & 0 & 0 & 0 & 0 & 0 & $x$ & 0 & 0,08 & 8,33 & 0,083 \\
\hline C24 & 0 & 0,5 & 0,5 & $x$ & 0 & 0,5 & 0 & 0,5 & 0 & 0 & 0 & 0 & 0 & 0 & 0,18 & 17,86 & 0,179 \\
\hline $\mathrm{C} 25$ & 0 & 0,5 & 0,5 & 0,5 & 0 & $x$ & 0 & 0 & 0 & 0 & 0 & 0 & 0 & 0 & 0,12 & 11,54 & 0,115 \\
\hline C26 & -- & 0 & 0 & 0,5 & 0 & 0,5 & 0 & 0,5 & 0,5 & 0,5 & 0 & $x$ & 0,5 & 0,5 & 0,27 & 26,92 & 0,269 \\
\hline $\mathrm{C} 27$ & 0 & 0,5 & 0,5 & 0 & 0 & 0 & -- & --- & $x$ & $x$ & $x$ & $x$ & $x$ & $x$ & 0,17 & 16,67 & 0,167 \\
\hline $\mathrm{C} 28$ & 0,5 & 0 & 0 & 0,5 & 0 & 0,5 & 0 & 0,5 & 0,5 & 0,5 & 0 & $x$ & 0,5 & 0 & 0,27 & 26,92 & 0,269 \\
\hline C29 & 0,0 & 0,5 & 0,5 & 0,5 & 0 & $x$ & 0 & 0,5 & 0 & 0 & 0 & $x$ & 0 & 0 & 0,19 & 19,23 & 0,192 \\
\hline C30 & 0 & 0,5 & 0 & $x$ & 0 & - & 0 & 0,5 & $x$ & $x$ & 0 & $x$ & 0 & 0 & 0,10 & 10,00 & 0,100 \\
\hline C31 & 0 & 0 & 0,5 & 0,5 & 0 & -- & 0 & 0 & 0 & 0 & 0 & $x$ & 0 & 0 & 0,08 & 7,69 & 0,077 \\
\hline C32 & 0,00 & 0,00 & 0,50 & 0,00 & 0,00 & 0,00 & 0,00 & 0,50 & 0,00 & 0,00 & 0,00 & 0,00 & 0,00 & 0,00 & 1,14 & 14,29 & 0,071 \\
\hline C33 & 0,50 & 0,00 & 0,50 & 0,50 & 0,00 & 0,00 & 0,00 & 0,50 & 0,00 & 0,00 & 0,00 & 0,00 & 0,00 & 0,00 & 1,29 & 28,57 & 0,143 \\
\hline C34 & 0,00 & 0,00 & 0,50 & 0,50 & 0,00 & 0,00 & 0,00 & 0,50 & 0,00 & 0,00 & 0,00 & 0,00 & 0,00 & 0,00 & 1,21 & 21,43 & 0,107 \\
\hline C35 & 0,00 & 0,00 & 0,50 & 0,50 & 0,00 & 0,00 & 0,00 & 0,50 & 0,00 & 0,00 & 0,00 & 0,00 & 0,00 & 0,00 & 1,21 & 21,43 & 0,107 \\
\hline C36 & 0,00 & 0,50 & 0,00 & 0,50 & 0,00 & 0,50 & 0,00 & 0,50 & 0,00 & 0,00 & 0,00 & 0,00 & 0,00 & 0,00 & 1,29 & 28,57 & 0,143 \\
\hline C37 & 0,50 & 0,50 & 0,50 & 0,50 & 0,00 & 0,50 & 0,00 & 0,50 & 0,00 & 0,00 & 0,00 & 0,00 & 0.00 & 0,50 & 1,50 & 50,00 & 0,230 \\
\hline C38 & 0,00 & 0,50 & 0,50 & 0,00 & 0,00 & 0,50 & 0,00 & 0,50 & 0,00 & 0,00 & 0,00 & 0,00 & 0,00 & 0,00 & 1,29 & 28,57 & 0,143 \\
\hline C39 & 0,00 & 0,50 & 0,50 & 0,50 & 0,00 & 0,00 & 0,00 & 0,50 & 0,00 & 0,00 & 0,00 & 0,00 & 0,00 & 0,00 & 1,29 & 28,57 & 0,143 \\
\hline $\mathrm{C} 40$ & 0,50 & 0,50 & 0,50 & 0,50 & 0,00 & 0,50 & 0,00 & 0,50 & 0,00 & 0,50 & 0,50 & 0,00 & 0,50 & 0,00 & 1,64 & 64,29 & 0,321 \\
\hline C41 & 0,00 & 0,50 & 0,50 & 0,50 & 0,00 & 0,00 & 0,00 & 0,50 & 0,00 & 0,00 & 0,00 & 0,00 & 0,00 & 0,00 & 1,29 & 28,57 & 0,143 \\
\hline $\mathrm{C} 42$ & 0,50 & 0,50 & 0,50 & 0,50 & 0,00 & 0,00 & 0,00 & 0,50 & 0,00 & 0,50 & 0,50 & 0,00 & 0,50 & 0,00 & 1,57 & 57,14 & 0,286 \\
\hline C43 & 0,00 & 0,00 & 0,50 & 0,50 & 0,00 & 0,50 & 0,00 & 0,50 & 0,00 & 0,00 & 0,00 & 0,00 & 0,00 & 0,00 & 1,29 & 28,57 & 0,143 \\
\hline C44 & 0,00 & 0,00 & 0,50 & 0,5 & 0,00 & 0,00 & 0,00 & 0,50 & 0,00 & 0,00 & 0,00 & 0,00 & 0,00 & 0,00 & 1,21 & 21,43 & 0,107 \\
\hline C45 & 0,50 & 0,50 & 0,00 & 0,50 & 0,00 & 0,50 & 0,00 & 0,50 & 0,50 & 0,50 & 0,00 & 0,00 & 0,50 & 0,00 & 1,57 & 57,14 & 0,286 \\
\hline C46 & 0,00 & 0,50 & 0,50 & 0,50 & 0,00 & 0,00 & 0,00 & 0,50 & 0,00 & 0,00 & 0,00 & 0,00 & 0,00 & 0,00 & 1,29 & 28,57 & 0,143 \\
\hline C47 & 0,50 & 0,50 & 0,50 & 0,50 & 0,00 & 0,00 & 0,00 & 0,00 & 0,00 & 0,00 & 0,00 & 0,00 & 0,00 & 0,00 & 1,29 & 28,57 & 0,143 \\
\hline C48 & 0,00 & 0,00 & 0,00 & 0.50 & 0,00 & 0,00 & 0,00 & 0,50 & 0,50 & 0,50 & 0,00 & 0,50 & 0,00 & 0,00 & 1,36 & 35,71 & 0,179 \\
\hline C49 & 0,00 & 0,00 & 0,00 & 0,00 & 0.00 & 0,50 & 0,00 & 0,50 & 0,00 & 0,00 & 0,00 & 0,50 & 0,00 & 0,00 & 1,21 & 21,43 & 0,107 \\
\hline C50 & 0,50 & 0,00 & 0,00 & 0,00 & 0,00 & 0,50 & 0,00 & 0,00 & 0,00 & 0,00 & 0,00 & 0,00 & 0,00 & 0,00 & 1,14 & 14,29 & 0,071 \\
\hline C51 & 0,00 & 0,50 & 0,50 & 0,50 & 0,00 & 0,00 & 0,00 & 0,00 & 0,00 & 0,00 & 0,00 & 0,00 & 0,00 & 0,00 & 1,21 & 21,43 & 0,107 \\
\hline
\end{tabular}


Tabela 2. (Continuação)

\begin{tabular}{|c|c|c|c|c|c|c|c|c|c|c|c|c|c|c|c|c|c|}
\hline \multirow{3}{*}{ Acesso } & \multicolumn{14}{|c|}{ Locos } & \multirow{3}{*}{ A } & \multirow{3}{*}{$\mathbf{P}$} & \multirow{3}{*}{ H } \\
\hline & Got-1 & Got-2 & Skdh-1 & Acp-1 & Fum-1 & Aco-1 & $\begin{array}{c}\text { G6 } \\
\text { pdh-1 }\end{array}$ & $\begin{array}{c}\text { G6 } \\
\text { pdh-2 }\end{array}$ & $\begin{array}{c}6 \\
\text { pgdh-1 }\end{array}$ & $\begin{array}{c}6 \\
\text { pgdh-2 }\end{array}$ & $\begin{array}{c}6 \\
2 \text { pgdh }-3\end{array}$ & Pgi-1 & Pgi-2 & Pgi-3 & & & \\
\hline & $h$ & $h$ & $h$ & $h$ & $h$ & $h$ & $\mathrm{~h}$ & $\mathrm{~h}$ & $h$ & $h$ & $h$ & $h$ & h & $h$ & & & \\
\hline C52 & 0,00 & 0,00 & 0,00 & 0,00 & 0,00 & 0,00 & 0,00 & 0,50 & 0,00 & 0,00 & 0,00 & 0,00 & 0,00 & 0,00 & 1,07 & 7,14 & 0,036 \\
\hline C53 & 0,00 & 0,50 & 0,50 & 0,50 & 0,00 & 0,00 & 0,00 & 0,50 & 0,00 & 0,00 & 0,00 & 0,00 & 0,00 & 0,00 & 1,29 & 28,57 & 0,143 \\
\hline C54 & 0,00 & 0,00 & 0,00 & 0,00 & 0,00 & 0,50 & 0,00 & 0,00 & 0,00 & 0,00 & 0,00 & 0,00 & 0,00 & 0,00 & 1,07 & 7,14 & 0,036 \\
\hline C55 & 0,00 & 0,00 & 0,00 & 0,50 & 0,00 & 0,00 & 0,00 & 0,50 & 0,00 & 0,50 & 0,50 & 0,00 & 0,50 & 0,50 & 1,43 & 42,86 & 0,214 \\
\hline C56 & 0,00 & 0,00 & 0,00 & 0,50 & 0,00 & 0,00 & 0,00 & 0,50 & 0,00 & 0,50 & 0,50 & 0,00 & 0,50 & 0,50 & 1,43 & 42,86 & 0,214 \\
\hline C57 & 0,50 & 0,00 & 0,50 & 0,50 & 0,00 & 0,00 & 0,00 & 0,50 & 0,00 & 0,00 & 0,00 & 0,00 & 0,00 & 0,00 & 1,29 & 8,57 & 0,143 \\
\hline C58 & 0,50 & 0,00 & 0,00 & 0,50 & 0,00 & 0,00 & 0,00 & 0,50 & 0,00 & 0,00 & 0,00 & 0,00 & 0,00 & 0,00 & 1,21 & 21,43 & 0,107 \\
\hline C59 & 0,00 & 0,00 & & & & & 0,00 & 0,50 & 00 & 0,00 & $0, C$ & &, 00 & 0,00 & 1,07 & 14 & 036 \\
\hline $\mathrm{C} 60$ & 0,50 & 0,00 & 0,00 & 0,00 & 0,00 & 0,50 & 0,00 & 0,50 & 0,50 & 0,50 & 0,00 & 0,50 & 0,00 & 0,00 & 1,43 & 42,86 & 0,214 \\
\hline C61 & 0,50 & 0,00 & 0,00 & 0,50 & 0,00 & 0,0 & 0,00 & 0,50 & 0,00 & 0,00 & 0,00 & $0, C$ & 0,00 & 0,00 & 1,21 & 21,43 & 0,107 \\
\hline C62 & 0,00 & 0,00 & 0,50 & 0,00 & 0,00 & 0,50 & 0,00 & 0,50 & 0,00 & 0,00 & 0,00 & 0,00 & 0,00 & 0,00 & 1,21 & 21,43 & 0,107 \\
\hline C63 & 0,50 & 0,00 & 0,50 & 0,00 & 0,00 & 0,50 & 0,00 & 0,50 & 0,00 & 0,00 & 0,50 & 0,00 & 0,50 & 0,50 & 1,50 & 50,00 & 0,250 \\
\hline C64 & 0,00 & 0,00 & 0,00 & 0,50 & 0,00 & 0,00 & 0,00 & 0,50 & 0,00 & 0,00 & 0,50 & 0,00 & 0,50 & 0,50 & 1,36 & 35,71 & 0,179 \\
\hline C65 & 0,00 & 0,00 & 0,50 & 0,50 & 0,00 & 0,00 & 0,00 & 0,50 & 0,00 & 0,00 & 0,00 & 0, & 0,00 & 0,00 & 1,21 & 21,43 & 0,107 \\
\hline C66 & 0,50 & 0,00 & 0,00 & 0,50 & 0,00 & 0,00 & 0,00 & 0,50 & 0,00 & 0,00 & 0,00 & 0,00 & 0,00 & 0,00 & 1,21 & 21,43 & 0,107 \\
\hline C67 & 0,5 & & & & & & 0,00 & & 0,0 & 0,00 & 0, & 0 , & 0, & 0, & 1,21 & 1,43 & 0,107 \\
\hline C68 & 0,00 & 0,50 & 0,50 & 0,00 & 0,00 & 0,00 & 0,00 & 0,50 & 0,00 & 0,00 & 0,00 & 0,00 & 0,00 & 0,00 & 1,21 & 21,43 & 0,107 \\
\hline C69 & 0,50 & 0,00 & & 0,00 & & & 0,00 & & 0,00 & 0,00 & 0,00 & 0,00 & 0,00 & 0, & 1,29 & 28,57 & 0,143 \\
\hline C70 & 0,50 & 0,00 & 0,50 & 0,50 & 0,00 & 0,50 & 0,00 & 0,50 & 0,00 & 0,00 & 0,00 & 0,00 & 0,00 & 0,00 & 1,36 & 35,71 & 0,179 \\
\hline C71 & 0,00 & 0,00 & 0,00 & 0,00 & 0,00 & 0,00 & 0,00 & 0,50 & 0,00 & 0,00 & 0,00 & 0,00 & 0,00 & 0,00 & 1,07 & 7,14 & 0,036 \\
\hline $\mathrm{C} 72$ & 0,00 & 0,00 & 0,50 & 0,00 & 0,00 & 0,50 & 0,00 & 0,50 & 0,00 & 0,00 & 0,00 & 0,00 & 0,00 & 0,00 & 1,21 & 21,43 & 0,107 \\
\hline $\mathrm{C} 73$ & 0,50 & 0,00 & 0,50 & 0,50 & 0,00 & 0,50 & 0,00 & 0,50 & 0,00 & 0,50 & 0,50 & 0,00 & 0,50 & 0,50 & 1,64 & 4,29 & 0,321 \\
\hline C74 & 0,50 & 0,00 & 0,00 & 0,50 & 0,00 & 0,00 & 0,00 & 0,50 & 0,50 & 0,50 & 0,50 & 0,50 & 0,50 & 0,50 & 1,64 & 64,29 & 0,321 \\
\hline $\mathrm{C} 75$ & 0,00 & 0,50 & 0,50 & 0,50 & 0,00 & 0,50 & 0,00 & 0,50 & 0,00 & 0,00 & 0,00 & 0,00 & 0,00 & 0,00 & 1,36 & 35,71 & 0,179 \\
\hline C76 & 0,50 & 0,50 & 0,00 & 0,50 & 0,00 & 0,00 & 0,00 & 0,50 & 0,00 & 0,00 & 0,00 & 0,00 & 0,00 & 0,00 & 1,29 & 28,57 & 0,143 \\
\hline C77 & 0,50 & 0,50 & 0,00 & 0,50 & 0,00 & 0,00 & 0,00 & 0,50 & 0,00 & 0,50 & 0,50 & 0,00 & 0,50 & 0,50 & 1,57 & 57,74 & 0,286 \\
\hline C78 & 0,50 & 0,50 & 0,50 & 0,50 & 0,00 & 0,00 & 0,00 & 0,50 & 0,00 & 0,50 & 0,50 & 0,00 & 0,50 & 0,50 & 1,64 & 64,29 & 0,321 \\
\hline
\end{tabular}

(x) representa inexistência de banda e (-) representa inconsistência na definição da banda.

clones, correspondente à quase metade dos clones examinados.

Os valores de similaridade genética variaram de $65 \%$ a $100 \%$, sendo que 70 dos 78 acessos analisados apresentaram similaridade dentro de grupos/ subgrupos. Tais resultados ratificam a base genética estreita da pimenta-doreino referida em literatura (ZEVEN, 1974). Os clones mais divergentes em relação ao conjunto foram os dos grupos G1, G2 e G3.

Os resultados obtidos permitem concluir que, dentre os locos examinados, os que apresentaram maior polimorfismo foram G6pdh-2, Acp-1 e Skdh-1. O número médio de alelos por locos variou de 0,04 a 1,64; a porcentagem de locos polimórficos variou de $3,57 \%$ a $64,29 \%$; e a heterozigosidade média variou de 0,036 a 0,321 . Os clones examinados foram altamente similares, com o mínimo de $65 \%$, e os clones mais divergentes em relação ao conjunto foram os pertencentes aos grupos G1, G2 e G3 e poderão ser utilizados para obtenção de genótipos superiores.

\section{AGRADECIMENTOS}

À JICA pelos materiais, equipamentos e reagentes doados durante o convênio de cooperação científica e tecnológica com a Embrapa Amazônia Oriental e ao FUNTEC, que complementou este estudo.

\section{LITERATURA CITADA}

BABBEL, J.R., SELANDER, R.K. Genetic variability in edaphically restricted aid widespread plant species. Evolution, v.26, p.619-630, 1974.

BROWN, A.H.D., WEIR, B.S. Measuring genetic variability in plant populations. In: Tanksley, S.D. (Ed.), Orton, T.J. (Ed.). Isozymes in plant genetics and breeding. Part A. Amsterdan: Elsevier Science Publishers, 1983. p.73-86.
CHELIAK, W.M., PITEL, J.A. Techniques for starch gel electrophoresis of enzymes from forest tree species. Petawawa National Forestry Institute: CanadianForestryService, S.1: 1984. 49 p. (Information Report PI-X-42).

CORTEZ, M.C., HUNZIKER, J.H. Isozymes in Larrea divaricata and Larrea tridentata (Zigophyllaceae): a study of two amphitropical vicariants and autopolyploidy. Genetica, v.101, p.115-124, 1997.

HAMRICK, J.L., LOVELESS, M.D. Isozyme variation in tropical trees: procedures e preliminary results. Biotropica, v.18, n.3, p.201-207, 1986.

HORACEK, J., ACANOVÁ, M. Glucose-6phosphate-isomerase as a marker of a fertility restorer gene in rape. Czech Journal Plant breeding, v.39, n.4, p.130-133, 2003.

IBGE. Área destinada à colheita, área colhida, quantidade produzida, rendimento médio e valor da produção dos principais produtos das lavouras permanentes, segundo as Grandes Regiões e Unidades da Federação. Disponível em <htth:Ilibge.gov.Br>. Acesso em 28 de mai. 2004. ILARSLAM, H., HORNER, H.T., PALMER, R.G., Genetics and citology of a new male-sterile, female-fertile soybean mutant. Crop science, v.39, p.58-64, 1999. 
MARTINS, C.S., POLTRONIERI, M.C., KANASHIRO, M., ALVES, R.M., GAIA, J.M., IKETANI, H., KAJITA, T. Caracterização bioquímica de germoplasma de fruteiras. In: Embrapa. Centro de Pesquisa Agroflorestal da Amazônia Oriental. Geração de tecnologia agroindustrial para o desenvolvimento do trópico úmido. Belém: EMBRAPA-CPATU/JICA, 1996. 305 p. p.161172. (EMBRAPA-CPATU. Documentos, 85).

MATHEW, P.M. Karyomorphological studies in Piper nigrum L. J. Plant Crops, v.1 (suppl.), p.1518, 1973.

MEDINA-FILHO, H.P. Linkage of Aps-1 Mi and other markers on choromossome 6. Rep. Tomato Genet. Coop., v.30, p.26-28, 1980.

NEALE, D.B., WEBER, J.C., ADAMS, W.T. Inheritance of needle tissue isozymes in Douglasfir Canadian Journal of Genetics and Citology, v.26, p.459-468, 1984.

NEI, M. Analysis of gene diversity in subdivided populations. Proceedings National Academy Science, v.70, n.12, p.3321-3323, 1972.

NEI, M. Molecular evolucionary genetics. New York: Columbia University Press. 1987. 512 p.
PERTERS, I., JAIN, S. Genetcs of grain amaranths: III. Gene-cytoplasmic male sterility. The Journal Of Heredity, v.78, n.4, p.251-256, 1987.

RODRIGUES, J.L., Pimenta-do-reino. s.l., Manaus, Secretaria de Produção. Setor de Relações Públicas, 1967. 21 p. (PRODAPAM. série 5, n.2). ROMERO, G.O., AMANTE-BORDEOS, A.D., DALMACIO, R.D., ELLORAN, R., SITCH, L.A. Comparative studies of isozymes in Oriza sativa e O. Minuta, and their interspecific evidence for homoeology and recombination. Theoretical and Applied Genetics, v.87, p.609-615, 1993.

TAKAHASHI, M., TSUMURA, Y., NAKAMURA, T., UCHIDA, K., OHBA, K. Alozyme variation of Fagus crenata in northeastern Japan. Canadian Journal of Forestry Research,v.24, p.1071-1074, 1994.

SHEPHERD, G.J. Fitopac 1. Manual do usuário. Campinas: UNICAMP, 2001. 93 p.

TORGGLER, M.G.F.; CONTEL, E. TORGGLER, S. 1995. Isozimas: variabilidade genética em plantas. Ribeirão Preto: Sociedade Brasileira de Genética, 175 p.
TSUMURA, Y., TOMARU, N., SUYAMA, Y., NA'EIM, M., OHBA, K. Laboratory manual of isozyme analysis. Bull. Tsukuba Univ.Forest., Tsukuba, v.6, p.63-95, 1990.

VIANA, J.M.S., CRUZ, C.D., BARROS, E.G., CARNEIRO, P.C.S. Genética. v.2. Viçosa: UFV, $2001.475 \mathrm{p}$.

WAARD, P.W.F. ZEVEN, A.C. Pepper: Piper nigrum L. In: FERRWERDA, F.P. (Ed.), WIT, F. (Ed.). Outlines of perenial crop breeding in the tropics. Wageningen, 1969. p.409-426 (Miscellaneous Paper, 4).

WAN, J., IKEHASHI, H. Identification of two types of differentiation in cultivated rice (Oriza sativa $\mathrm{L}$.) detected by polymorphism of isozymes and hybrid sterility. Euphytica, v.94, p.151-161, 1997.

ZEVEN, A.C. Black pepper, Piper nigrum (Piperaceae). In: SIMMONDS, N.W. (Ed.). Evolution of crop plants. New York: Logman, 1974. 339 p. p.234-235. 